\title{
Suckling Rat Colon Synthesizes and Processes Active Lactase-Phlorizin Hydrolase Immunologically Identical to that from Jejunum
}

\author{
HANS A. BÜLLER, EDMOND H. H. M. RINGS, ROBERT K. MONTGOMERY,
} MARIANA A. SYBICKI, AND RICHARD J. GRAND

Division of Pediatric Gastroenterology and Nutrition, Department of Pediatrics, The Floating Hospital, New England Medical Center, Tufts University School of Medicine, Boston, Massachusetts 02111

\begin{abstract}
To identify potential tissue-specific characteristics of intestinal glycoprotein synthesis and processing, rat intestinal lactase-phlorizin hydrolase $(\mathrm{L}-\mathrm{Ph})$ was studied after pulse-labeling of colonic explants from 5-d-old suckling rats in organ culture and the data compared to similar studies in rat jejunum. Histologic sections of 5-dold proximal colon showed villus-like structures lined with columnar epithelial cells. Lactase and phlorizin hydrolase activities showed tissue-specific developmental patterns. Using a MAb to small intestinal $\mathrm{L}-\mathrm{Ph}$, we were able to immunoprecipitate from colon at different ages a protein that hydrolyzed lactose and phlorizin, and whose activity was not inhibited by $p$-chloromercuribenzoate. After pulselabeling for $\mathbf{6 0} \mathrm{min}$ and chase for $\mathbf{3 0} \mathrm{min}$, immunoprecipitated L-Ph from total homogenates of rat colonic explants appeared on fluorography of SDS-PAGE as one band of approximately $205 \mathrm{kD}$. With increasing time of chase, it took $240 \mathrm{~min}$ before the precursor form was converted to the intermediate form (equivalent to the $180-\mathrm{kD}$ form in jejunum) and the mature form (equivalent to the $130-\mathrm{kD}$ form in jejunum), although these conversions in the jejunum were observed within $60 \mathrm{~min}$ of chase, and only $\mathbf{3 0}$ min of pulse labeling. When compared on SDS-PAGE to immunoprecipitated jejunal $\mathrm{L}-\mathrm{Ph}$, the precursor form in the colon had a slightly higher apparent mol wt than the corresponding precursor form found in the endoplasmic reticulum-Golgi fraction of the jejunum. The intermediate as well as the mature $\mathrm{L}-\mathrm{Ph}$ forms in the colon were also both somewhat higher in apparent molecular weight than the same bands in the microvillus membrane fraction from jejunal explants. Removal of $\mathrm{N}$-linked oligosaccharides from jejunum and colonic forms of $\mathrm{L}-\mathrm{Ph}$ produced bands on SDS-PAGE with identical mobility, suggesting that the proteins were the same. The data demonstrate that, in neonatal colon, enzymatically active $\mathrm{L}-\mathrm{Ph}$ undergoes biosynthetic and processing events similar to those in the jejunum. During early life, colonic L-Ph may function in the salvage of lactose not absorbed in the small intestine. (Pediatr Res 26: 232-236, 1989)
\end{abstract}

\section{Abbreviations}

MVM, microvillus membrane

PCMB, $p$-chloromercuribenzoate

Received February 6, 1989; accepted May 6, 1989.

Correspondence Richard J. Grand, M.D., Division of Pediatric Gastroenterology and Nutrition, Floating Hospital, New England Medical Center, 750 Washington St., Box 213, Boston, MA 02111.

Supported in part by Nutricia, Zoetermeer, The Nethlerlands (H.A.B.), National Institutes of Health Research Grants DK 32658 (R.J.G.), the National Dairy Council, and Grant P30 DK 34928 to the Center for Gastroenterology Research on Absorptive and Secretory Processes.
Lactase-phlorizin hydrolase is a major intestinal hydrolytic enzyme of particular importance in early life of most mammals, and is found chiefly in the jejunum, although extensive studies on potential other localization beyond the small intestine are lacking. Most biochemical studies of microvillar hydrolases have focused on the small intestine, and comparatively little is known about differentiation of specific enzymes in the colon. The adult colon functions primarily in the regulation of salt and water transport and bacterial fermentation. The fetal and newborn colon, however, differs considerably in morphology and probably function from that of the adult. In the rat fetus, the proximal colon is populated by villi and microvilli after the formation of the gut lumen and retains this form until 10 days after birth (1, 2).

The most extensive developmental studies of the morphology and enzyme patterns of the colonic epithelium in the fetal and newborn rat have been performed by Helander $(1,3)$, identifying the functional development of acid and alkaline phosphatase, carbonic anhydrase, and $\beta$-d-galactosidase. However, the measurement of $\beta$-d-galactosidase activity did not distinguish between the three different intestinal galactosidase forms (4). Perinatal changes in the activity of $\beta$-galactosidase of lysosomal origin in the rat colon have been extensively described by Koldovsky et al. (5) and Litin (6). Colony and Neutra (2) have also investigated the epithelial differentiation of fetal rat colon in conjunction with the appearance of alkaline phosphatases. Human colonic development and enzymatic distribution were studied in both fetuses and preterm newborns (7-11).

In our study, we have used techniques established in our laboratory in the study of suckling jejunum (12) to investigate the biosynthesis and function of lactase-phlorizin hydrolase in the early postnatal rat colon. To the best of our knowledge, there has been no report describing the biosynthesis and demonstrating the presence of an active lactase-phlorizin hydrolase enzyme in the colon of newborn animals or human.

\section{MATERIALS AND METHODS}

Animals. Sprague-Dawley CD rats were purchased from Charles River Breeding Laboratories, Wilmington, MA. All animals were housed in a constant temperature and humidity environment on a 12-h light-dark cycle. Animals were allowed to suckle ad libitum, and the dams were fed standard laboratory food and water ad libitum. The times for all animal procedures were kept constant throughout the study.

Materials. Cell labeling grade $\left[{ }^{35}\right.$ S $]$ methionine $(670.8 \mathrm{Ci} /$ $\mathrm{mmol}$ ), and $\mathrm{En}^{3} \mathrm{Hance}$ were from Du Pont-New England Nuclear, Boston, MA. Methionine-free Dulbecco's modified Eagle's medium was from Irvine Scientific, Santa Ana, CA. N-glycanase was purchased from Genzyme, Boston, MA. 
Antibodies. The MAb (13) used in these experiments is the same as described previously (12). The hybridoma cells (YBB 2/ 61) were a generous gift of Dr. Andrea Quaroni of Cornell University, Ithaca, NY. The cells were cultured in our laboratory and injected into pristane-primed BALB/c mice from which ascites fluid was obtained. $\mathrm{IgG}_{1}$ was purified from the ascites fluid by affinity chromatography on a protein A-CL Sepharose 4B (Pharmacia Fine Chemicals, Piscataway, NJ) column (14). The eluates were dissolved in coupling buffer and covalently coupled to cyanogen bromide-activated Sepharose according to manufacturer's instructions.

Homogenization. For the measurement of the specific activity of lactase and phlorizin hydrolase we used homogenates of colon tissue immediately distal to the cecum, and of the middle third of the small intestine. In the younger animals up to $9 \mathrm{~d}$, the homogenates were made from total intestine, whereas, in the adult, intestinal mucosa was obtained by scraping. Homogenization was performed in a buffer containing $10 \mathrm{mM}$ HEPES/ $\mathrm{HCl}, \mathrm{pH} 7.5,20 \mathrm{mM} \mathrm{NaCl}, 0.5 \%$ Triton $\mathrm{X}-100$, and the protease inhibitors as described earlier (12). In some experiments, MVM and ER-Golgi fractions of jejunal explants were prepared (12). All lactase and phlorizin hydrolase activities were measured in the presence of PCMB to inhibit lysosomal $\beta$-galactosidase activity $(4,5,12)$. The lactase assay was performed as described (12), whereas the phlorizin hydrolase assay was performed according to the technique described by Malathi and Crane (15).

Organ culture and immunoprecipitation. Organ culture of colon explants of 5-d-old rats was performed according to the method previously described for jejunal explants (12). For immunoprecipitation, the colon explants were homogenized in HEPES/Triton buffer as described above. After centrifugation at $30000 \times g$ for $10 \mathrm{~min}$, the supernatant was incubated overnight at $4^{\circ} \mathrm{C}$ with $150 \mu \mathrm{L}$ of MAb bound to Sepharose. Washing and analysis of the immune complex by SDS-PAGE was as described (12). Staphylococcus aureus V8 digestions were performed in the slots of $12 \%$ or $15 \%$ gels on individual lactase bands that were first cut out of $5 \%$ gels. For the preparation and digestion of the gel slices we followed the techniques described by Cleveland et al. (16).

$N$-glycanase treatment. N-glycanase hydrolyzes asparaginelinked oligosaccharides (high mannose, complex and hybrid chains) of glycoproteins (17). The digestion of immunoprecipitates was carried out as follows. The protein bound to the Sepharose beads was boiled for $3 \mathrm{~min}$ in a buffer containing $0.5 \%$ SDS and $0.1 \mathrm{M} \beta$-mercaptoethanol. The sample was diluted with $0.55 \mathrm{M}$ sodium phosphate buffer, $\mathrm{pH} 8.6$, containing albu$\min 6 \mathrm{mg} / \mathrm{mL}$ and Nonidet P-40 in a final concentration of $1.25 \%$ (as outlined in the manufacturer's instructions). Incubation with $\mathrm{N}$-glycanase $(0.25 \mathrm{U})$ was done overnight at $37^{\circ} \mathrm{C}$. After incubation, the sample was analyzed by SDS-PAGE, as described previously (12).

\section{RESULTS}

Histology of newborn rat colonic epithelium. Figure 1 shows light microscopy of 5-d-old rat colon distal to the cecum. As described previously by others $(1,3,18,19)$, small intestinal-like villi are apparent. Electron microscopy revealed that the villi were covered with regular microvilli somewhat reduced in number compared to jejunum (data not shown, see Ref. 1-3). Thus, in comparison to the adult, the newborn rat colon is still morphologically immature at birth and has small intestine-like features.

Lactase and phlorizin hydrolase activities in jejunum and colon of newborn and adult rats. The sp act of jejunal and colonic lactase and phlorizin hydrolase at several time points during postnatal development and adulthood are depicted in Figure 2. There was a steady increase in lactase-specific activity in the jejunum toward the end of the 1 st wk of life which was absent in the colon. The ratio between lactase activity in the jejunum

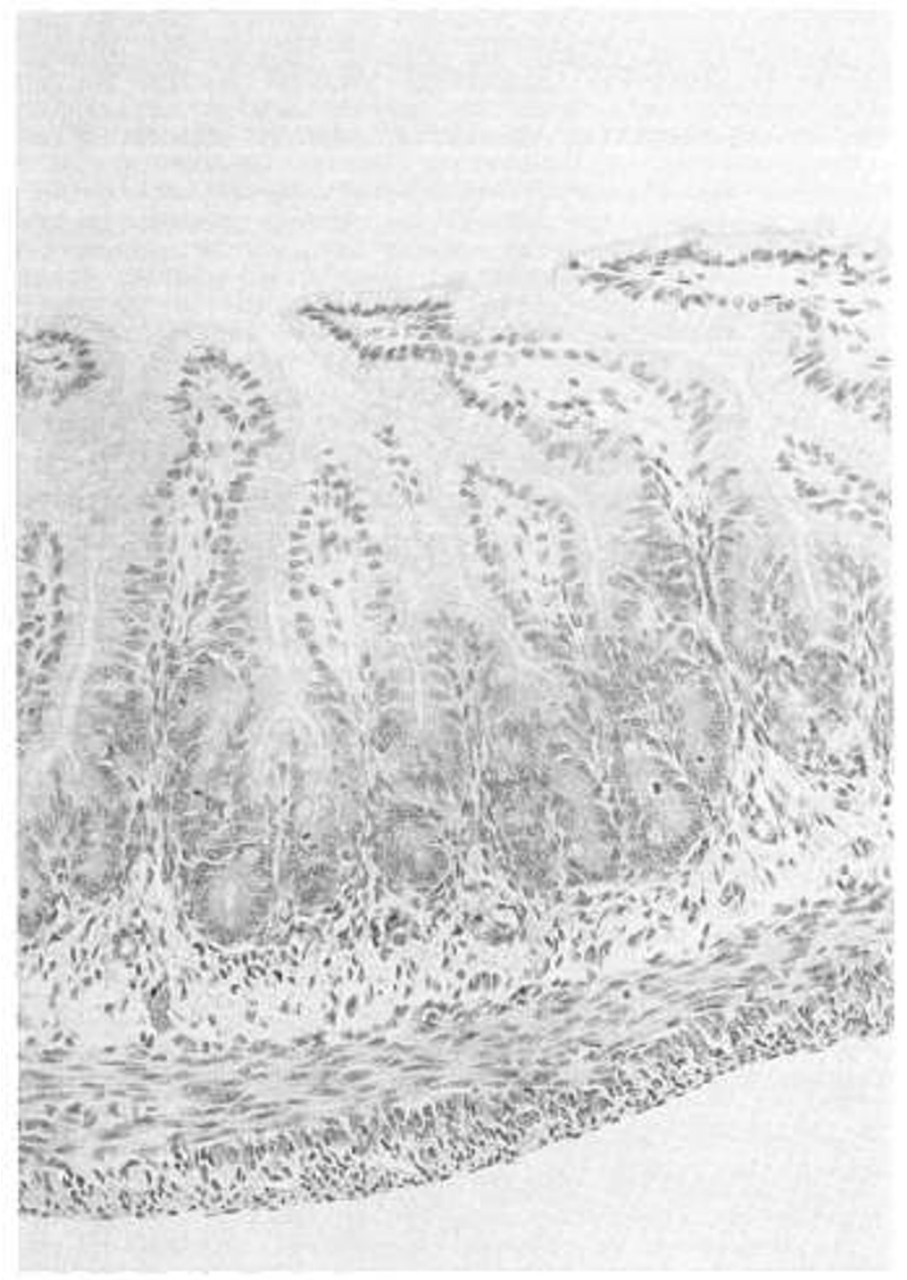

Fig. 1. Light microscopy of 5-d-old rat colon distal to the cecum. Small intestine-like villi are apparent, as are abundant columnar epithelial cells, goblet cells, and lamina propria (hematoxylin and eosin, $\times$ 580).

and that in the colon varied from 3.5:1 (at d 1) to 10:1 (at d 6). Phlorizin hydrolase activities in jejunum and colon parallelled each other at almost all ages; in contrast to lactase, phlorizin hydrolase reached its peak very early in the 1 st wk of life. It is noteworthy that we were never able to measure phlorizin hydrolase activity in the colon of the 1-d-old rat, whereas there was high activity measured at $3 \mathrm{~d}$ of age. The same pattern of lactase and phlorizin hydrolase activities were observed when the enzyme assays were performed on the thoroughly washed immune complexes obtained after precipitation with the MAb (data not shown).

Lactase-phlorizin hydrolase in jejunum and colon. Figure 3 shows the different forms of lactase-phlorizin hydrolase in jejunum and colon obtained on SDS-PAGE. In our previous study of the jejunum (12), the apparent mol wt of the intracellular form was estimated to be $220 \mathrm{kD}$, and the same $220 \mathrm{kD}$ form was inserted into the MVM followed by the two-step cleavage to the $180-$ and $130-\mathrm{kD}$ band, respectively (Fig. 3, lane 3). Reexamination of the precursor bands on 5\% SDS-PAGE revealed a clear size difference between the high mannose, intracellular precursor form (205 kD, Fig. 3, lane 1) and the mature, fully glycosylated precursor form $(220 \mathrm{kD})$ inserted into the MVM (Fig. 3, lane 3). Comparison of these with the three forms found in the colon, as depicted in Figure 3, lane 2, shows that each colonic form has a somewhat higher apparent mol wt than its comparable jejunal form. The $220-\mathrm{kD}$ precursor form found in jejunum was never observed in the colon.

Pulse-chase labeling of lactase-phlorizin hydrolase in colon. 


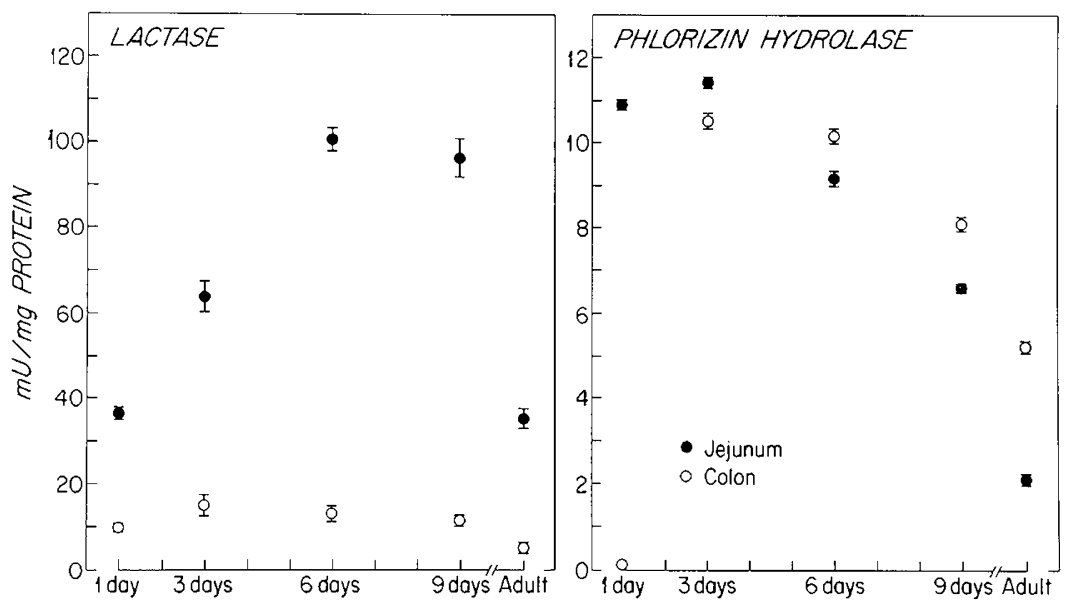

Fig. 2. Lactase and phlorizin hydrolase-specific activities in jejunum and colon of rats at varying ages. Total homogenates were prepared, and enzyme and protein contents measured as described in "Materials and methods." Each point represents measurements from at least four different animals, and are expressed as mean \pm SEM.

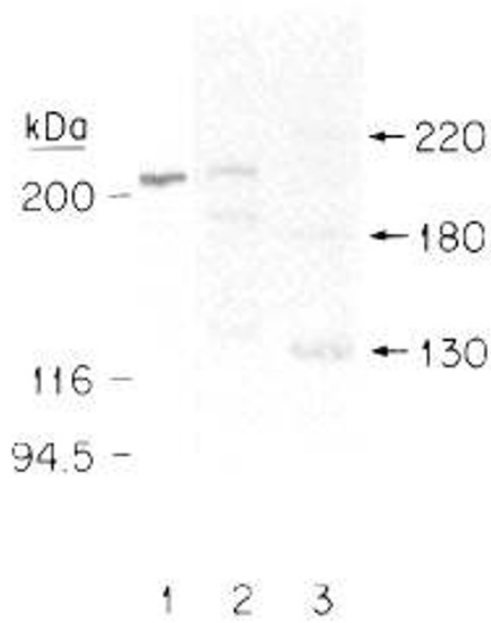

Fig. 3. SDS-PAGE and fluorography of immunoprecipitated lactasephlorizin hydrolase from jejunum and colon of 5-d-old rats. Jejunal explants were pulse-labeled with $\left[{ }^{35} \mathrm{~S}\right]$ methionine for $30 \mathrm{~min}$ and either used immediately (lane 1) or chased for 120 min (lane 3) with 460-fold excess unlabeled methionine. Colon explants were pulse-labeled for 60 min and chased for 240 min (lane 2). All samples shown were electrophoresed on the same $5 \%$ polyacrylamide gel and processed as described under "Materials and methods." Lane 1 shows the jejunal intracellular (ER-Golgi) form, and lane 3 the jejunal MVM forms of lactase-phlorizin hydrolase. Lane 2 represents the forms immunoprecipitated from total colonic homogenates. The bars at the left indicate the positions of the mol wt standards; the size of the labeled jejunal MVM bands are given at the right (arrows).

Figure 4 shows the labeling pattern of lactase-phlorizin hydrolase in proximal colon of 5 -d-old rats. After a 60 -min pulse with $\left[{ }^{35} \mathrm{~S}\right]$ methionine, the label was chased for $0,30,60,120$, and 240 min. Labeling of the precursor band of $205 \mathrm{kD}$ was observed after $30 \mathrm{~min}$ of chase; this is approximately $1 \mathrm{~h}$ slower than in the jejunum, where, after a 30-min pulse, the precursor was identified immediately intracellularly, without any chase (12). This band persisted at 60 and $120 \mathrm{~min}$ of chase without further processing; although a faint band seen above the $205-\mathrm{kD}$ precursor (lanes 3 and 4) may represent maturation of the high mannose form. Processing to the intermediate and mature forms in the colon was very slow; only after $240 \mathrm{~min}$ of chase did the bands equivalent to the jejunal 180- and 130-kD bands appear (lane 6). In contrast, in the jejunum, both bands were already apparent after a 30 -min pulse and a 90-min chase (12). The two

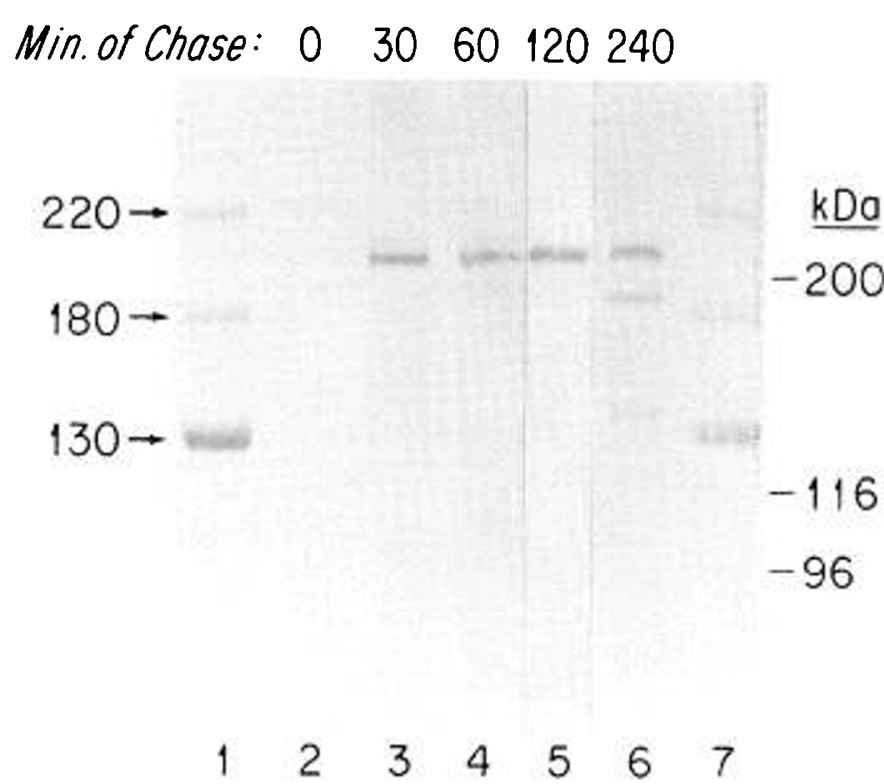

Fig. 4. SDS-PAGE and fluorography of immunoprecipitated lactasephlorizin hydrolase from jejunum and colon of 5-d-old rats. Pulse labeling and chase were as described in Figure 3. All samples shown were electrophoresed in the same $5 \%$ polyacrylamide gel and processed as described in "Materials and methods." Lanes $l$ and 7 represent jejunal MVM forms. Lanes 2 to 6 show the forms immunoprecipitated from total colonic homogenates at various times of chase. The bars at the right indicate the positions of the mol wt standards; the sizes of the labeled jejunal bands are given at the left (arrows).

outer lanes of Figure 4 (lanes 1 and 7) show the immunoprecipitated lactase-phlorizin hydrolase patterns in the MVM fraction of jejunal explants of 5-d-old rats, pulsed for $60 \mathrm{~min}$ and chased for $120 \mathrm{~min}$.

$N$-glycanase treatment of lactase-phlorizin hydrolase from jejunum and colon. As shown above (Fig. 3) the jejunal and colonic forms of the enzyme differ in mol wt. In Figure 5, the different forms in colon and jejunum depicted in Figure 3 were analyzed after removal of $\mathrm{N}$-linked oligosaccharides by $\mathrm{N}$-glycanase. As shown in Figure 5, lane 1 , the apparent $\mathrm{M}_{\mathrm{r}}$ of the endoplastic reticulum-Golgi precursor was decreased to $195 \mathrm{kD}$. A comparable shift (to $195 \mathrm{kD}$ ) was seen in the precursor band in the colon, formerly found to be just above $205 \mathrm{kD}$ (Fig. 3, lane 2). In addition, the other colonic forms, previously found at just above 180 and $130 \mathrm{kD}$ (Fig. 3), were now reduced proportionally, 


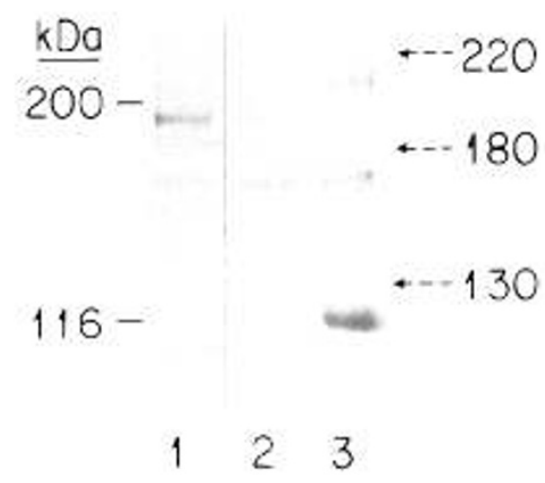

Fig. 5. SDS-PAGE and fluorography of immunoprecipitated lactasephlorizin hydrolase from jejunum and colon of 5-d-old rats following $\mathrm{N}$ glycanase treatment. All procedures were as described in Figure 3, except that after immunoprecipitation, the fractions were treated with $\mathrm{N}$-glycanase as described in "Materials and methods." The bars at the left indicate the positions of the mol wt standards. The dashed arrows at the right indicate the position of the three MVM forms before $\mathrm{N}$-glycanase treatment.

and showed mobility equal to the N-glycanase-treated 180- and $130-\mathrm{kD}$ bands found in the jejunal MVM (Fig. 5 compared to Fig. 3). The MVM 220-kD band in the jejunum was reduced in $M_{r}$ but not completely deglycosylated if compared with the intracellular precursor in Figure 3, lane 3, indicating the presence of $O$-linked glycosylation. These results confirm the identity of the lactase-phlorizin hydrolase protein found in jejunum and colon. In addition, comparison of peptide patterns following V8 protease digestion of the jejunal and colonic proteins also indicates that the two proteins are very similar (data not shown).

\section{DISCUSSION}

In this report, we have described the biosynthesis of an enzymatically active, important digestive enzyme, lactase-phlorizin hydrolase, in the proximal large intestine of newborn rats. Previous work from our laboratory described a corresponding synthesis pattern in the jejunum of 5-d-old rats (12). Rat colonic histology in the first $2 \mathrm{wk}$ of life differs dramatically from that found in the adult colon $(1,18,19)$. The newborn proximal colon is populated by numerous villi of various sizes and shapes, which are retained until $10 \mathrm{~d}$ after birth, when the villus loss due to constriction in the basal region of the villi is completed (1, 18). Adult colon is marked by flat epithelium with crypts of Lieberkuhn $(1,18)$, and limited active absorption of nutrients (19). In contrast, several reports provide evidence of efficient transport of nutrients in the newborn rat colon (19-21). Morphology of the human fetal colon $(7,9,11)$ also shows small intestine-like features such as the presence of villi, which only disappear around the time of birth. In the preterm infant (11), accelerated morphologic maturation has been observed independent of feeding.

As mentioned above, most studies concerning enzyme development in the rat colon were performed in fetal material (1-3, 22 ). In the nursing period of all placental mammals, except the sea lion (23), lactose is the major carbohydrate ingested. Only two studies, one in the human (11) and another in rat (3), have been performed to identify the presence of this very important disaccharidase in the colon in early postnatal life. The report by Helander (3), however, did not assay lactase-phlorizin hydrolase alone. There are three different galactosidases $(4,5)$ in the intestine; one is located in the lysosome and is referred to as an acidic galactosidase; the second form is found in the cytoplasm and is known as the cytosolic or heterogalactosidase; and the third form is called neutral galactosidase, but it is better known as lactase-phlorizin hydrolase, located in the MVM of the enterocyte. The activity of these different forms can be distinguished by $\mathrm{pH}$ optimum, substrate specificity, and sensitivity to the inhibitor PCMB. In Helander's study (3), however, the $\mathrm{pH}$ of 5.5 , the absence of PCMB, and the use of $O$-nitrophenylgalactoside as the substrate, which can be hydrolyzed by all three galactosidases, makes interpretation of his findings difficult.

Raul et al. (11) studied human colon from infants born after 28 or more wk of gestation and showed significant sucrase, glucoamylase, and aminopeptidase activities, but were never able to measure any lactase activity in that period. In earlier work (9), they were also unable to detect lactase activity in colonic material of fetuses obtained between 8-30 wk. This is in contrast to work by both Dahlquist and Lindberg (8) and Menard and Pothier (24) which clearly showed that in the period they studied (11-23 wk) lactase activity was present in the human colon. One of the possible explanations for the failure of Raul et al. (11) to find lactase activity could lie in the temperature instability of lactase, especially if assays are performed using postmortem material. Moreover, we have also found lactase to be degraded very rapidly in the absence of protease inhibitors (Büller HA, unpublished data). Thus, the presumed absence of lactase activity from human colon in previous studies could be due to technical factors.

In our study, we found lactase and phlorizin hydrolase activity in the homogenates as well as in immunoprecipitates of rat colon. The different patterns of development of lactase and phlorizin hydrolase in the colon and small intestine are obvious (Fig. 2), and are supported by similar findings in small intestine of neonatal rats by Birkenmeier and Alpers (25). They are in contrast, however, with studies by Colombo et al. (26), which showed that the two enzyme activities in the small intestine increased and decreased in a very similar fashion. Further information regarding the active site(s) in lactase-phlorizin hydrolase will be needed in order to reconcile these differences. The immune complex obtained after incubation with the MAb bound to Sepharose beads showed activity against both lactose and phlorizin. Analysis of this complex by SDS-PAGE identified only one major band of approximately $130 \mathrm{kD}$, suggesting that lactase and phlorizin hydrolase are one or two active sites on the same peptide.

Cousineau and Green (27) found differences in molecular size between the proximal and distal forms of lactase-phlorizin hydrolase chromatographically purified from the small intestine of the suckling rat. In confirming their finding, we observed the same difference in molecular mass between immunoprecipitated lactase-phlorizin hydrolase from the jejunum and ileum (data not shown). These molecular size changes are identical to the differences we have shown in this report between jejunum and colon. Neuraminidase treatment, which removes sialic acid residues, abolished the electrophoretic differences between the proximal and distal forms (27), suggesting that altered glycosylation accounts for the molecular size differences. Similarly, we were able to confirm that the mobility differences on SDS-PAGE between the jejunal and colonic forms are eliminated after removal of $\mathrm{N}$-linked oligosaccharides.

When the intracellular and MVM forms of jejunal lactasephlorizin hydrolase were compared by SDS-PAGE to identically treated colon preparations, after $\mathrm{N}$-glycanase treatment, the initial precursor of $205 \mathrm{kD}$, the intermediate $180-\mathrm{kD}$ and the mature $130-\mathrm{kD}$ bands showed the same migration pattern in both jejunum and colon. These findings indicate that the $M_{r}$ differences in the lactase-phlorizin hydrolase bands observed in jejunum and colon were based on the presence of different N-linked oligosaccharides. Organ specific differences in glycosylation have also been found for human ribonucleases (28). We therefore hypothesize that the $\mathrm{M}_{\mathrm{r}}$ differences in lactase-phlorizin hydrolase found along the intestinal tract reflect region-specific glycosylation.

The apparent slow synthesis and processing of lactase-phlorizin hydrolase in the colon is unexplained. It takes approximately 5 $\mathrm{h}$ after starting labeling before the mature $130 \mathrm{kD}$-like band is found in the colon, whereas the jejunal mature protein is already 
labeled after $90 \mathrm{~min}$. It is interesting to note that in human jejunal explants, this processing to the mature form takes at least $3 \mathrm{~h}$ (29), whereas in the colon adenocarcinoma cell line Caco-2 (30), lactase-phlorizin hydrolase, in contrast to other microvillus membrane hydrolases, exhibits extremely slow synthesis, processing, and transport (approximately $16 \mathrm{~h}$ of chase).

The transport studies described previously $(19,20)$ are interesting in the light of this report, because not only can glucose be transported by the colon through the first $5 \mathrm{~d}$ of life in the rat, but it is now clear that the colon in the newborn rat contains a key enzyme that generates glucose as an absorbable product. It is known that lactose is malabsorbed in the small intestine of human premature infants and newborns, and reaches the colon $(31,32)$. Two mechanisms may be responsible for the salvage of the lactose not absorbed by the small intestine: fermentation to short chain fatty acids $(31,32)$, or hydrolysis of lactose by lactasephlorizin hydrolase located on colonic villi. Thus, it seems possible that lactase-phlorizin hydrolase in the newborn rat colon plays a role in the absorption of unhydrolyzed lactose.

\section{REFERENCES}

1. Helander HF 1973 Morphological studies on the development of the rat colon. Acta Anat 85:153-176

2. Colony PC, Neutra MR 1983 Epithelial differentiation in the fetal rat colon. Dev Biol 97:349-363

3. Helander HF 1975 Enzyme patterns and protein absorption in rat colon during development. Acta Anat 91:330-349

4. Asp NG, Dahlqvist A 1972 Human small intestine $\beta$-galactosidases: specific assay of three different enzymes. Anal Biochem 47:527-538

5. Koldovsky O, Asp NG, Dahlqvist A 1969 A method for assay of neutral and acid $\beta$-galactosidase in homogenates of rat small-intestinal mucosa. Anal Biochem 27:409-418

6. Litin BS, Koldovsky O 1982 Perinatal changes in activity of lysosomal glycosidases in rat colon. Biol Neonate 42:228-238

7. Lev R, Orlic D 1974 Histochemical and radioautographic studies of normal human fetal colon. Histochemistry 39:301-311

8. Dahlqvist A, Lindberg T 1966 Development of the intestinal disaccharidase and alkaline phophatase activities in the human foetus. Clin Sci 30:517-528

9. Lacroix B, Kedinger M, Simon-Assmann P, Rousset M, Zweibaum A, Haffen K 1984 Developmental pattern of brush border enzymes in the human fetal colon. Correlation with some morphogenetic events. Early Hum Dev 9:95103

10. Triadou N, Zweibaum A 1985 Maturation of sucrase-isomaltase complex in human fetal small and large intestine during gestation. Pediatr Res 19:136138

11. Raul F, Lacroix B, Aprahamian M 1986 Longitudinal distribution of brush border hydrolases and morphological maturation in the intestine of the preterm infant. Early Hum Dev 13:225-234
12. Büller HA, Montgomery RK, Sasak WV, Grand RJ 1987 Biosynthesis glycosylation and intracellular transport of intestinal lactase-phlorizin hydrolase in rat. $\mathbf{J}$ Biol Chem 262:17206-17211

13. Quaroni A, Isselbacher KJ 1985 Study of intestinal cell differentation with monoclonal antibodies to intestinal cell surface components. Dev Biol 111:267-279

14. Ey PL, Prowse SJ, Jenkin CR 1978 Isolation of pure IgG1, IgG2a, and IgG2b immunoglobulins from mouse serum using protein A-sepharose. Immunochemistry 15:429-436

15. Malathi P, Crane RK 1969 Phlorizin hydrolase: a $\beta$-glucosidase of hamster intestinal brush border membrane. Biochim Biophys Acta 173:245-256

16. Cleveland DW, Fischer SG, Kirschner MW, Laemmli UK 1977 Peptide mapping by limited proteolysis in sodium dodecyl sulfate and analysis by gel electrophoresis. J Biol Chem 252:1102-1106

17. Plummer TH, Elder JH, Alexander S, Phelan AW, Tarentino AL 1984 Demonstration of peptide: $\mathrm{N}$-glycosidase $\mathrm{F}$ activity in endo- $\beta$-N-acetylglucosaminidase $F$ preparations. J Biol Chem 259:10700-10704

18. Ono K 1980 Changes of the caecal villi during postnatal development in rats. Cell Tissue Res 208:253-259

19. Potter GD, Lester R 1984 The developing colon and nutrition. J Pediatr Gastroenterol Nutr 3:485-487

20. Batt ER, Schachter D 1969 Developmental pattern of some transport mechanisms in newborn rats and mice. Am J Physiol 216:1064-1068

21. Ono K 1977 Absorption of horseradish peroxidase by the principal cells of the large intestines of postnatal developing rats. Anat Embryol 151:53-62

22. Smith T, Christianson K, Moss R, Bailey D 1985 Structural and biochemical differentiation of the guinea-pig colon during foetal development. Cell Tissue Res 242:197-209

23. Kretchmer N 1971 Memorial Lecture: lactose and lactase-a historical perspective. Gastroenterology 61:805-813

24. Menard D, Pothier P 1987 Differential distribution of digestive enzymes in isolated epithelial cells from developing human fetal small intestine and colon. J Pediatr Gastroenterol Nutr 6:509-516

25. Birkenmeier E, Alpers DH 1974 Enzymatic properties of rat lactase-phlorizin hydrolase. Biochim Biophys Acta 350:100-112

26. Colombo V, Lorenz-Meyer H, Semenza G 1973 Small intestinal phlorizin hydrolase: the " $\beta$-glycosidase complex." Biochim Biophys Acta 327:412-424

27. Cousineau J, Green JR 1980 Isolation and characterization of the proximal and distal forms of lactase-phlorizin hydrolase from the small intestine of the suckling rat. Biochim Biophys Acta 615:147-157

28. Yamashita K, Hitoi A, Irie M, Kobata A 1986 Fractionation by lectin affinity chromatography indicates that the glycosylation of most ribonucleases in human viscera and body fluids is organ specific. Arch Biochem Biophys 250:263-266

29. Naim HY, Sterchi EE, Lentze MJ 1987 Biosynthesis and maturation of lactase phlorizin hydrolase in the human small intestinal epithelial cells. Biochem $\mathbf{J}$ 241:427-434

30. Hauri HP, Sterchi EE, Bienz D, Fransen JAM, Marxer A 1985 Expression and intracellular transport of microvillus membrane hydrolases in the human intestinal epithelial cells. J Cell Biol 101:838-851

31. MacLean WC, Fink BB 1980 Lactose malabsorption by premature infants: Magnitude and clinical significance. J Pediatr 97:383-388

32. Mobassaleh M, Montgomery RK, Biller JA, Grand RJ 1985 Development of carbohydrate absorption in the fetus and neonate. Pediatrics 75:160-166 